NASA/TM-2005-213823

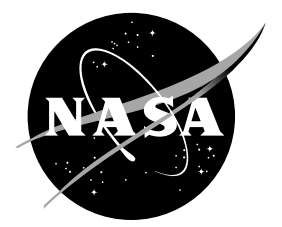

\title{
Parametric Investigation of Thrust Augmentation by Ejectors on a Pulsed Detonation Tube
}

Jack Wilson and Alexandru Sgondea

QSS Group, Inc., Cleveland, Ohio

Daniel E. Paxson and Bruce N. Rosenthal

Glenn Research Center, Cleveland, Ohio 
Since its founding, NASA has been dedicated to the advancement of aeronautics and space science. The NASA Scientific and Technical Information (STI) Program Office plays a key part in helping NASA maintain this important role.

The NASA STI Program Office is operated by Langley Research Center, the Lead Center for NASA's scientific and technical information. The NASA STI Program Office provides access to the NASA STI Database, the largest collection of aeronautical and space science STI in the world. The Program Office is also NASA's institutional mechanism for disseminating the results of its research and development activities. These results are published by NASA in the NASA STI Report Series, which includes the following report types:

- $\quad$ TECHNICAL PUBLICATION. Reports of completed research or a major significant phase of research that present the results of NASA programs and include extensive data or theoretical analysis. Includes compilations of significant scientific and technical data and information deemed to be of continuing reference value. NASA's counterpart of peerreviewed formal professional papers but has less stringent limitations on manuscript length and extent of graphic presentations.

- TECHNICAL MEMORANDUM. Scientific and technical findings that are preliminary or of specialized interest, e.g., quick release reports, working papers, and bibliographies that contain minimal annotation. Does not contain extensive analysis.

- CONTRACTOR REPORT. Scientific and technical findings by NASA-sponsored contractors and grantees.
- CONFERENCE PUBLICATION. Collected papers from scientific and technical conferences, symposia, seminars, or other meetings sponsored or cosponsored by NASA.

- SPECIAL PUBLICATION. Scientific, technical, or historical information from NASA programs, projects, and missions, often concerned with subjects having substantial public interest.

- TECHNICAL TRANSLATION. Englishlanguage translations of foreign scientific and technical material pertinent to NASA's mission.

Specialized services that complement the STI Program Office's diverse offerings include creating custom thesauri, building customized databases, organizing and publishing research results ... even providing videos.

For more information about the NASA STI Program Office, see the following:

- Access the NASA STI Program Home Page at http://www.sti.nasa.gov

- E-mail your question via the Internet to help@sti.nasa.gov

- Fax your question to the NASA Access Help Desk at 301-621-0134

- Telephone the NASA Access Help Desk at 301-621-0390

- Write to:

NASA Access Help Desk

NASA Center for AeroSpace Information 7121 Standard Drive

Hanover, MD 21076 
NASA/TM-2005-213823

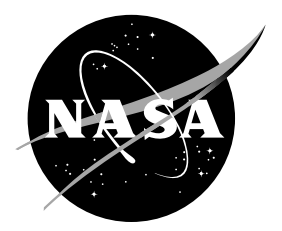

\section{Parametric Investigation of Thrust Augmentation by Ejectors on a Pulsed Detonation Tube}

Jack Wilson and Alexandru Sgondea

QSS Group, Inc., Cleveland, Ohio

Daniel E. Paxson and Bruce N. Rosenthal

Glenn Research Center, Cleveland, Ohio

Prepared for the

41st Joint Propulsion Conference

cosponsored by the AIAA, ASME, SAE, and ASEE

Tucson, Arizona, July 10-13, 2005

National Aeronautics and

Space Administration

Glenn Research Center 


\section{Acknowledgments}

The support of the Constant Volume Combustion Cycle Engine (CVCCE) project, directed by Leo Burkardt, is gratefully acknowledged.

Trade names or manufacturers' names are used in this report for identification only. This usage does not constitute an official endorsement, either expressed or implied, by the National Aeronautics and Space Administration.

\section{This work was sponsored by the Low Emissions Alternative}

Power Project of the Vehicle Systems Program at the NASA Glenn Research Center.

Available from

NASA Center for Aerospace Information 7121 Standard Drive

Hanover, MD 21076
National Technical Information Service 5285 Port Royal Road Springfield, VA 22100 


\title{
Parametric Investigation of Thrust Augmentation by Ejectors on a Pulsed Detonation Tube
}

\author{
Jack Wilson and Alexandru Sgondea \\ QSS Group, Inc. \\ Cleveland, Ohio 44135
}

Daniel E. Paxson and Bruce N. Rosenthal

National Aeronautics and Space Administration

Glenn Research Center

Cleveland, Ohio 44135

\begin{abstract}
A parametric investigation has been made of thrust augmentation of a 1 inch diameter pulsed detonation tube by ejectors. A set of ejectors was used which permitted variation of the ejector length, diameter, and nose radius, according to a statistical design of experiment scheme. The maximum augmentations for each ejector were fitted using a polynomial response surface, from which the optimum ejector diameters, and nose radius, were found. Thrust augmentations above a factor of 2 were measured. In these tests, the pulsed detonation device was run on approximately stoichiometric air-hydrogen mixtures, at a frequency of $20 \mathrm{~Hz}$. Later measurements at a frequency of $40 \mathrm{~Hz}$ gave lower values of thrust augmentation. Measurements of thrust augmentation as a function of ejector entrance to detonation tube exit distance showed two maxima, one with the ejector entrance upstream, and one downstream, of the detonation tube exit. A thrust augmentation of 2.5 was observed using a tapered ejector.
\end{abstract}

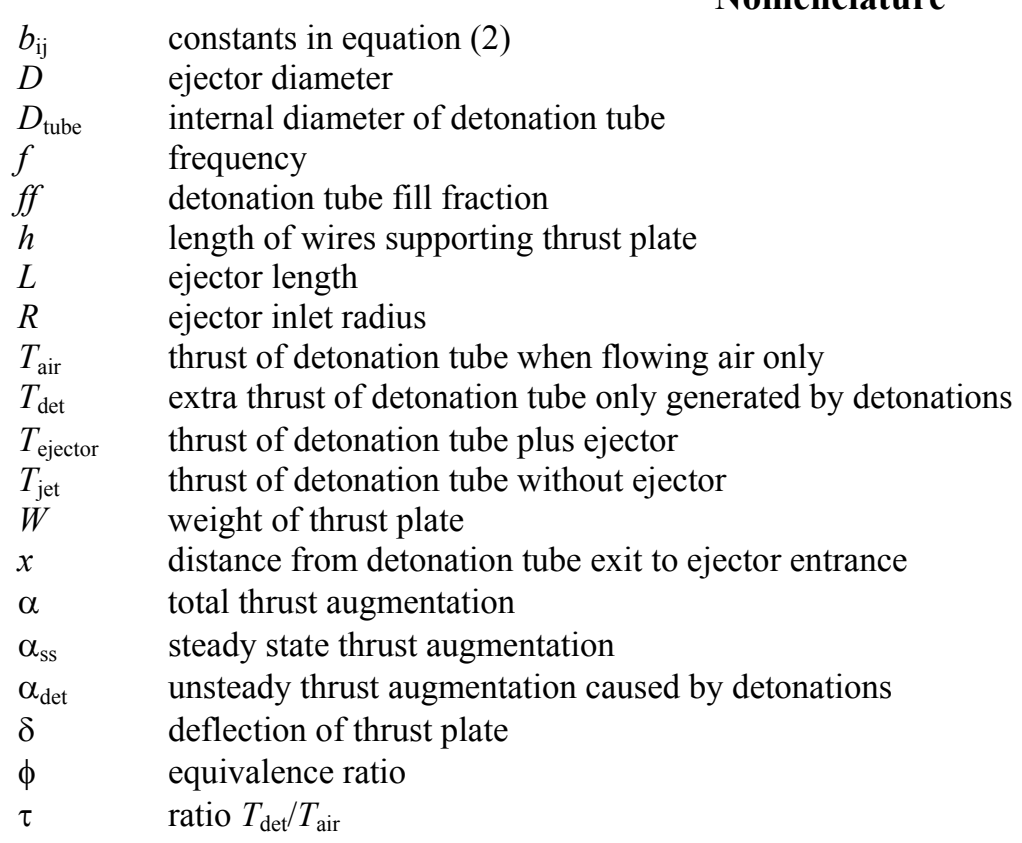




\section{Introduction}

The current interest in pulsed detonation engines for potential aerospace application has also spurred an interest in unsteady ejectors as a means of thrust augmentation. There have recently been several reports of experimental (refs. 1 to 3) and theoretical (ref. 4) investigations of thrust augmentation by pulsed detonation tubes, with conflicting results. Shehadeh, Saretto, Lee, Pal, and Santoro (ref. 1) used a constant diameter ejector, with an ejector diameter to detonation tube diameter of 2.55 , and found a maximum augmentation of 1.4 , when the ejector overlapped the detonation tube. Better performance was achieved when the nose of the ejector was rounded. Their experiments were performed at a frequency of $10 \mathrm{~Hz}$, with ethylene and oxygen-nitrogen mixtures. Allgood, Gutmark, Hoke, Bradley, and Schauer (ref. 2) found that the best position of the ejector was dependant on fill fraction. They used a constant ejector to tube diameter ratio of 2.75 , and tested both straight ejectors, and ejectors with a diverging tailpiece. Both types of ejector had a bell-mouth entrance. Their maximum thrust augmentation was 1.65 at a fill-fraction of 0.4 , with the ejector entrance downstream of the tube exit. Thrust augmentation decreased with increasing fill-fraction. The detonation tube was operated at a frequency of $30 \mathrm{~Hz}$, using stoichiometric airhydrogen mixtures. Rasheed, Tangirala, Pinard, and Dean (ref. 3) used three different ejectors to detonation tube diameter ratios of 1.5, 2, and 3, and also found that the best position of the ejector entrance was downstream of the tube exit, but only saw a thrust augmentation of 1.14. They used air-hydrogen mixtures, operating at $10 \mathrm{~Hz}$.

The initial objective of the present experiment was to use an existing set of ejectors to provide information on the optimum diameter, length, and nose radius, for ejectors driven by detonation pulses. This ejector set was used previously for thrust augmentation experiments using a pulsejet, (ref. 5) and a Hartmann-Sprenger tube (ref. 6) as the driver. The set provides three different diameters, with three different lengths, and three different nose radii, permitting a Box-Behnken statistical design of experiment. The experiment was performed on a detonation tube operating on air-hydrogen mixtures, at $20 \mathrm{~Hz}$. Later experiments involved increasing the ejector length beyond the values used in the statistical experiment, increasing the frequency, and testing a different ejector geometry, with virtually no straight section, so that it is an inlet section plus a long diffuser. This was called the tapered ejector.

\section{A. Detonation Tube}

\section{Apparatus}

An overall diagram of the apparatus is given in figure 1, and a photograph in figure 2(a). The detonation tube first used was 3 feet long, with an internal diameter of $1 \mathrm{inch}$, and an external diameter of 1.75 inches. Hydrogen is admitted under pressure by two high frequency valves (Parker-Hannifin Pulse Valves Model 91-200-900) into a small plenum, from where it is fed into the detonation tube via 8 passages in the face plate. Each passage is surrounded by three air passages, directed to impinge on the hydrogen a short distance from the face plate. The air is flowed continuously, but the hydrogen is pulsed. The air flow rate and the average hydrogen flow rate are measured with venturi meters. An Iota One Solenoid Valve Controller opens and closes the hydrogen valves, and provides a signal to fire the spark gap which triggers the detonation. A Shchelkin spiral 17 inches long, with 1 inch pitch, is inserted into the front end of the tube, to reduce the deflagration to detonation distance. Five ionization gauges, which are simply spark plugs, are provided from the middle of the tube towards the end, and spaced $10 \mathrm{~cm}$ apart, to measure the detonation speed. In practice, only three were used, as there appeared to be some interaction between the gauges when all five were used, resulting in spurious signals. In addition, a PCB high frequency pressure transducer, located 4.5 inches from the end of the tube, was initially used to monitor the pressure signal, to verify that a detonation had been achieved. A more detailed description of the detonation tube has been given by Opalski, Paxson, and Wernet (ref. 7).

The pressure transducer, plus the final ionization gauge, prevented ejector measurements from being made with the inlet of the ejector upstream of the detonation tube exit. Later, to permit such measurements, a new tube was made, with the last 9 inches of the tube having an external diameter of 1.5 inches. This made the tube external to internal diameter ratio in this region the same that of the tube used by Shehadeh et al. (ref. 1). This necessitated moving the ionization gauges, and the PCB pressure transducer upstream, figure 2(b).

Although the valves could be operated at up to $100 \mathrm{~Hz}$, reliable detonations proved difficult to achieve at high frequencies. Although detonations were generated at high frequencies, after a few seconds of operation the Shchelkin spiral blew out of the tube! The highest frequency that proved repeatable was $40 \mathrm{~Hz}$.

Experiments were typically run at a duty cycle around 50 percent. By duty cycle, what is meant is the ratio of the time during which hydrogen is admitted to the time between pulses. High duty cycles tended to result in overheating of the spiral. The flow rates were adjusted to give the desired equivalence ratio and fill fraction, which is the fraction of the tube that is filled with a fuel/air mixture. Inadvertently, the statistical experiment, plus the experiment to increase the ejector length were run at an equivalence ratio of 1.2, and a fill fraction of 1.4. Later experiments were made at an equivalence ratio of 1 , and a fill fraction of 1.05 . 


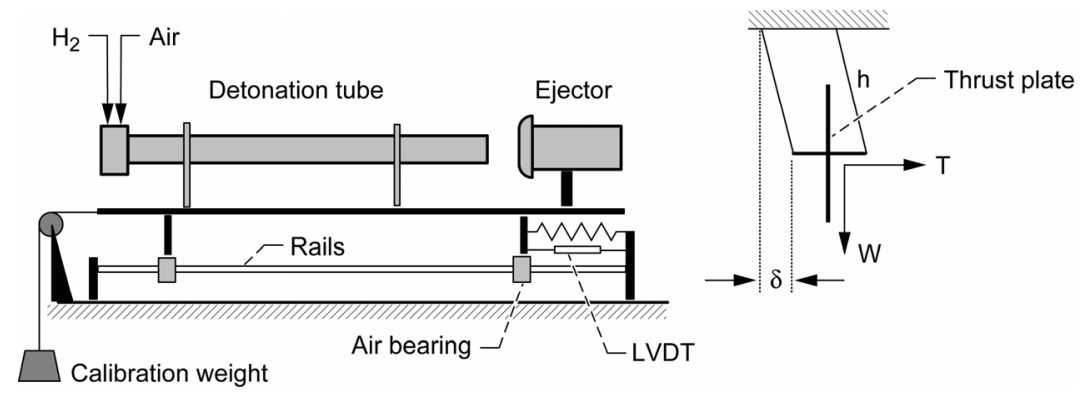

Figure 1.- Schematic diagram of the detonation tube, ejector, thrust plate, and thrust spring system.
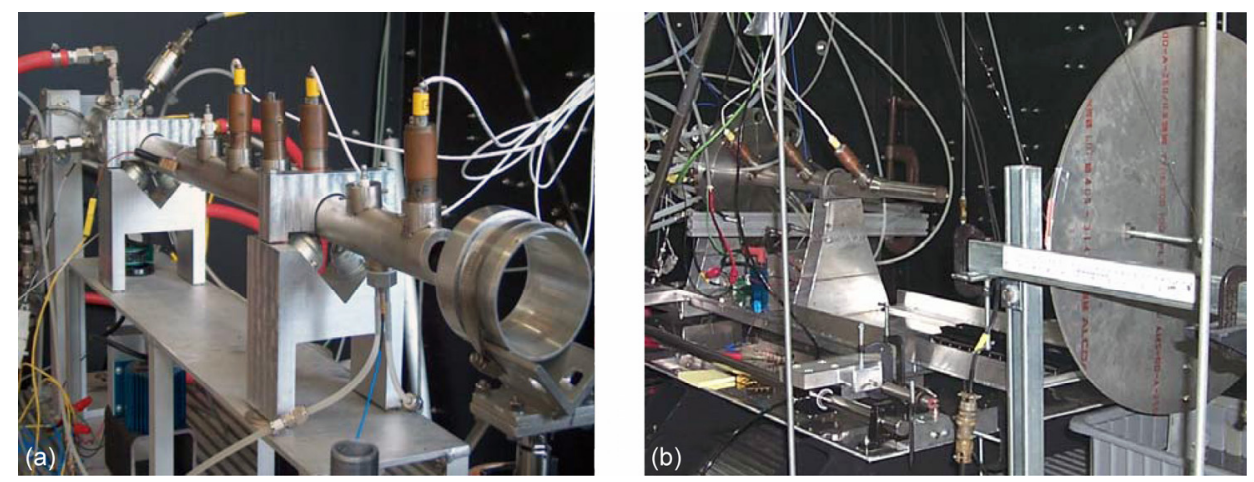

Figure 2(a).- Photograph of the original pulsed detonation tube, with the exit end pointing to the lower right. The short 3 inch diameter ejector is mounted downstream of the tube exit, and (b) the modified tube permitting the ejector entrance to be upstream of the tube exit, and mounted on air bearings for the spring extension technique of thrust measurements. The ballistic thrust plate can be seen at the right.

\section{B. Ejectors}

The set of ejectors for the statistical experiment is shown schematically in figure 3(a). At each ejector diameter there are two center sections, of different lengths, three inlets with nose radii of $0.25,0.5$, and 0.75 inches, and a diffuser section, which has a half-angle divergence of $5^{\circ}$. By either inserting the diffuser directly into the inlet, or using a center section, three different lengths are possible, roughly 3, 7.5, and 12.5 inches. Unfortunately, the inlets are not all the same length, so the exact length depends on which inlet is installed. The set comprises three different diameters, 2.2, 3, and 4 inches. The ejectors are mounted on a stand, which can be moved to adjust the ejector to tube exit distance.

One model of pulsed ejector performance is that the vortex rings produced by impulsively starting a flow act like a piston in pushing external air in front of it into the ejector, and pulling external air in behind it. This seems commensurate with the optimum ejector diameter being about the same size as the vortex ring. Since the ring grows slightly as it propagates away from the tube exit, this suggests that if an ejector was tapered so as to follow the vortex ring growth, it would be a better "fit", and hence a better piston. In order to verify this, a tapered ejector was built with a $4^{\circ}$ cone behind the throat, as shown in figure $3(\mathrm{~b})$. The ejector was built in sections so that by removing or adding sections, the length of the ejector could be altered. The throat was 3 inches in diameter, and lengths of $81 / 2$, $11,13 \frac{1}{2}$, and 16 inches were possible. The inlet radius was $3 / 4$ inch.

\section{Thrust Measurements}

Measurements of thrust, both with, and without an ejector in place, were made with a 21 inch diameter thrust plate, mounted 20 inches from the tube exit. Initially, the thrust plate was directly in front of a load cell, with the objective of obtaining the thrust reading from the load cell signal. In practice, the signal was strongly oscillatory, and extracting the DC component from it proved unreliable. Instead, the thrust plate was suspended from four wires, 

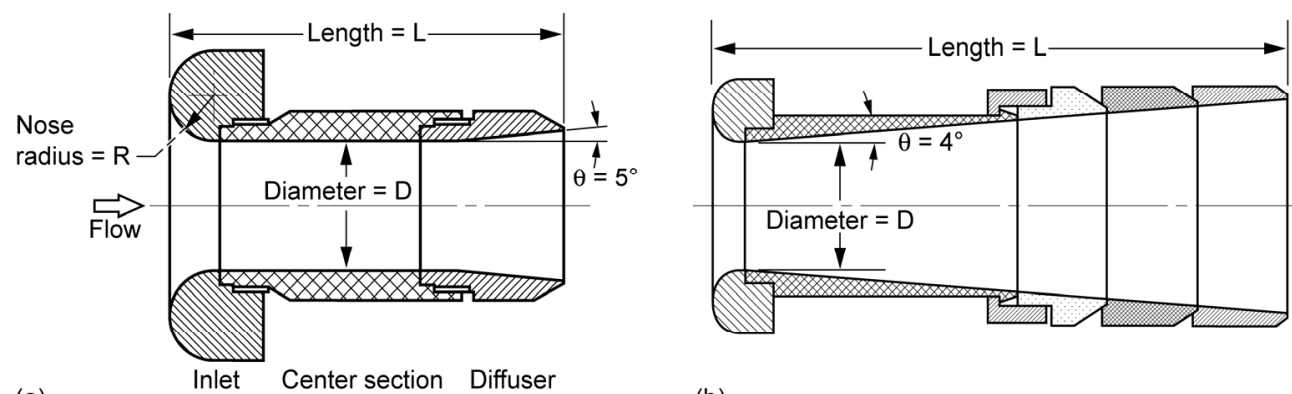

(a)

(b)

Figure 3(a).-Schematic diagram of the set of ejectors used in the statistical experiment and (b) the tapered ejector.

and used in a ballistic mode, i.e., by measuring the deflection, which is proportional to the thrust (for small deflections). A paddle attached to the thrust plate, and immersed in a tank of glycerine provided damping for the thrust plate. The deflection of the plate was recorded on a video camera, and the magnitude read off after the run. The net deflection was the final reading when fluctuations due to the impulsive start had died down minus the reading before the air was turned on. Thus the thrust due to the air flow alone is included in the thrust measurement. The thrust is $W \tan \left(\sin ^{-1}[\delta / h]\right)$.

Because the observed thrust amplification values seemed large compared with other workers, it was felt desirable to add an additional method of measuring thrust, and for later runs, a scheme similar to that used by Shehadeh et al. (ref. 1) was added. For this scheme, the pulsed detonation tube was mounted on a sled, which was supported by four air bearings sliding on stainless steel rails, as indicated in figure 1. This gave a very low friction support. Movement of the tube was restrained by one or more springs, depending on the level of thrust anticipated. The tube movement when it fired was monitored by a Transtek linear variable differential transformer, model 024000, with the signal displayed on a Datamax recorder. The device was calibrated by hanging weights from a cord attached to the tube, running horizontally to a pulley, and down to the weights. As with the thrust plate, oscillations were damped by two paddles attached to the detonation tube, and immersed in glycerine filled tanks. These are not shown in figure 1.

\section{The Experiment}

The initial experiment used a three level, three parameter Box-Behnken design (ref. 8). Such a design minimizes the runs necessary to get a good fit to the data. The exact set of runs, i.e., the combination of diameter, length, and nose radius to be used, is given in table 1 , together with the results.

In running the experiment, the thrust was measured for three firings of the detonation tube with no ejector in place. Each firing lasted 8 seconds. An ejector was then mounted at a given distance behind the detonation tube, and three firings made with the ejector. Following this, the ejector was removed, and the measurement of the thrust of the detonation tube alone was repeated. The ejector was next replaced at a different distance, and three measurements made. This procedure continued until an ejector to tube exit distance had been found which maximized the thrust augmentation. After that, three more measurements of the thrust of the detonation tube alone were made. All the thrust measurements of the detonation tube alone were averaged to give the thrust without an ejector, $\mathrm{T}_{\text {jet }}$. At each distance, the three thrust measurements made with an ejector were averaged to give the thrust at that distance, $\mathrm{T}_{\text {ejector}}$. The thrust augmentation is then given by:

$$
\alpha=T_{\text {ejector }} / T_{\text {jet }}
$$

A plot of the thrust augmentation versus distance between the tube exit and the ejector entrance is given in figure 4 , for the 2.2 inch diameter ejector at a length of 7.6 inches, with a nose radius of 0.75 inches. The estimated accuracy of the measurements is \pm 0.025 . These runs were made at a duty cycle of 70 percent, a fill fraction of 1.4 (i.e., the tube was overfilled), and an equivalence ratio of 1.2, at a frequency of $20 \mathrm{~Hz}$. 
TABLE 1.-SET OF RUNS COMPRISING THE BOX-BEHNKEN EXPERIMENTAL DESIGN, WITH RESULTS

\begin{tabular}{|l|l|l|l|l|l|}
\hline Run & $D$ & $L$ & $R$ & Optimum $x$ & $\alpha$ \\
\hline 1 & 2.2 & 3.125 & 0.5 & 0.5 & 1.34 \\
\hline 2 & 2.2 & 7.125 & 0.25 & 0.75 & 1.62 \\
\hline 3 & 2.2 & 7.625 & 0.75 & 1.0 & 1.70 \\
\hline 4 & 2.2 & 12.375 & 0.5 & 0.5 & 1.87 \\
\hline & & & & & \\
\hline 5 & 3 & 2.875 & 0.25 & 2.0 & 1.32 \\
\hline 6 & 3 & 3.375 & 0.75 & 1.75 & 1.42 \\
\hline 7 & 3 & 7.375 & 0.5 & 1.0 & 1.75 \\
\hline 8 & 3 & 7.375 & 0.5 & 1.0 & 1.72 \\
\hline 9 & 3 & 7.375 & 0.5 & 1.0 & 1.8 \\
\hline 10 & 3 & 12.125 & 0.25 & 1.5 & 1.91 \\
\hline 11 & 3 & 12.625 & 0.75 & 1.25 & 2.06 \\
\hline & & & & & \\
\hline 12 & 4 & 3.125 & 0.5 & 2.5 & 1.32 \\
\hline 13 & 4 & 7.125 & 0.25 & 3.5 & 1.49 \\
\hline 14 & 4 & 7.625 & 0.75 & 2.25 & 1.66 \\
\hline 15 & 4 & 12.375 & 0.5 & 2.0 & 1.85 \\
\hline
\end{tabular}

\section{A. The statistical experiment}

\section{Experimental Results}

The maximum thrust augmentation measured for a given combination of $D, L$, and $R$ is given in table 1 , together with the distance between detonation tube exit and ejector entrance at which that maximum was achieved. This distance is positive when the ejector entrance is downstream of the tube exit. As can be seen in figure 4, for the 2.2 inch diameter ejector, a maximum in thrust augmentation occurred with the ejector entrance downstream of the tube exit. This was true of all the ejectors tested in the statistical experiment. There is no obvious correlation between the distances for maximum thrust augmentation and the parameters $L, D$, and $R$, although they do seem to increase as $D$ increases. The thrust augmentation can be fitted with a response surface of the form:

$$
\alpha=b_{0}+b_{1} D+b_{2} L+b_{3} \mathrm{R}+b_{11} D^{2}+b_{22} L^{2}+b_{33} R^{2}+b_{12} D L+b_{13} D R+b_{23} L R
$$

The resulting values of the $b_{\mathrm{ij}}$ are given in table 2. The experimental values of thrust augmentation are plotted against ejector length in figure 5, together with contours from equation (2), for each ejector diameter, and for an inlet radius of 0.5 inches. It is clear that the thrust augmentation is increasing with ejector length. It is also clear that there is an optimum ejector diameter. Using the response surface to predict an optimum diameter gives a diameter of 3.2 inches, so that the optimum ejector to detonation tube diameter ratio is about 3.2, somewhat larger than the ratios used by most other workers. In evaluating the constants for table 2 , only terms with confidence greater than or equal to 96 percent were retained, except for $b_{33}$. Since there is a term $b_{13}$, the optimum diameter and inlet radius are related, and at a diameter of 3.2 inches the optimum inlet radius is 0.85 inches. The term $b_{33}$ has a confidence of only 80 percent, and if it were dropped, the optimum inlet radius would be even larger. From equation (2), the optimum ejector length is 17 inches. Because this value is beyond the range of the experimental space, it can not be considered accurate, and needs to be verified by measurements at longer ejector lengths.

TABLE 2.-VALUES OF THE CONSTANTS IN EQUATION (2) WHICH FIT THE OBSERVED HRUST AUGMENTATION DATA

\begin{tabular}{|l|c|c|c|c|c|c|c|c|c|c|}
\hline Constant & $b_{0}$ & $b_{1}$ & $b_{2}$ & $b_{3}$ & $b_{11}$ & $b_{22}$ & $b_{33}$ & $b_{12}$ & $b_{13}$ & $b_{23}$ \\
\hline Value & 0 & 0.6986 & 0.1140 & 0 & -0.1296 & -0.00336 & -0.2674 & 0 & 0.1498 & 0 \\
\hline
\end{tabular}

\section{B. Extension to longer length}

Since the statistical experiment showed that longer ejector lengths were desirable, it was decided to increase the length. Fortunately a longer length center section was available, providing an overall length of 17 inches. Only the 3 inch diameter ejector, with the 0.75 inch radius inlet was used, as this had been shown to have a performance close to the optimum. For this ejector, runs at lengths of 3.375 and 12.625 had been made in the statistical series, but no runs at a length of 7.625 inches. Consequently, additional runs with both 7.625 and 17 inch lengths were made. 


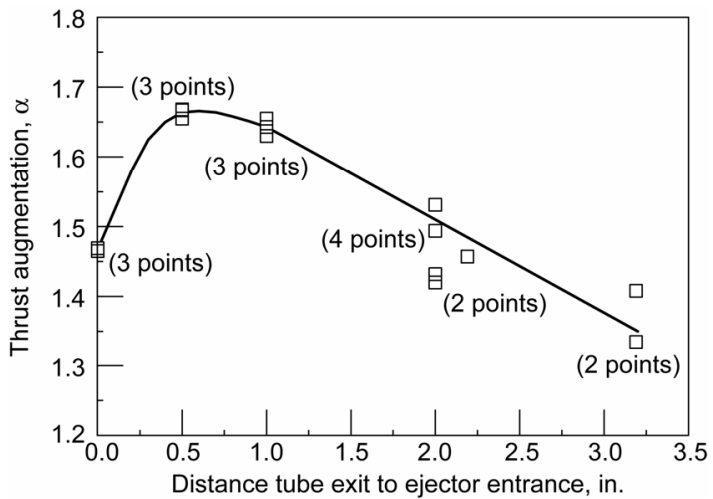

Figure 4.-Measurements of thrust augmentation on the 2.2 inch diameter, 7.6 inch long, 0.75 inch inlet radius ejector, as a function of detonation tube exit to ejector entrance distance. Frequency $=20 \mathrm{~Hz}, \phi=1.2$.

The results are in figure 6, together with a fitted curve. Surprisingly, the results with the 17 inch length showed less thrust amplification than those at 12.625 inches, and the optimum length seems to be 15 inches. These runs were also made at a duty cycle of 70 percent, fill fraction of 1.4 , $\phi=1.2$, and $v=20 \mathrm{~Hz}$.

\section{Effect of separation between ejector and pulsed detonation tube exit}

As stated above, different workers have observed the maximum in thrust augmentation as a function of the distance between detonation tube exit and ejector entrance at differing locations. Some have found a maximum with the ejector downstream of the detonation tube exit, others with it upstream. Thus it seemed useful to investigate this phenomenon. Although the thrust augmentation at an ejector length of 12.625 inches was found above to be higher than that at an ejector length of 17 inches, the latter length was chosen since it closely scaled the best ejector of Shehadeh et al. (ref. 1). The ejector diameter used was 3 inches, with a 0.75 inch inlet radius. For these runs, the modified detonation tube was used having the 9 inch long section of 1.5 inch outer diameter at the downstream end. The experiments were initially run at a frequency of $20 \mathrm{~Hz}, f f=1.05, \phi=1$, at a duty cycle of 55 percent, later at a frequency of $40 \mathrm{~Hz}$, $f f=1.05, \phi=1$, and a duty cycle of 60 percent. Three runs were made at each distance between ejector and tube exit, with two runs without an ejector between each distance setting, the latter being averaged to determine the base thrust. The results are shown in figure 7 . There appear to be maxima both for the ejector entrance upstream and for the ejector entrance downstream of the detonation tube. Also thrust augmentation decreases with increasing frequency.

\section{Tapered Ejector}

Finally, measurements of thrust augmentation were made with the tapered ejector (fig. 2(b)). It was desired to investigate the effects of length change with this ejector, and

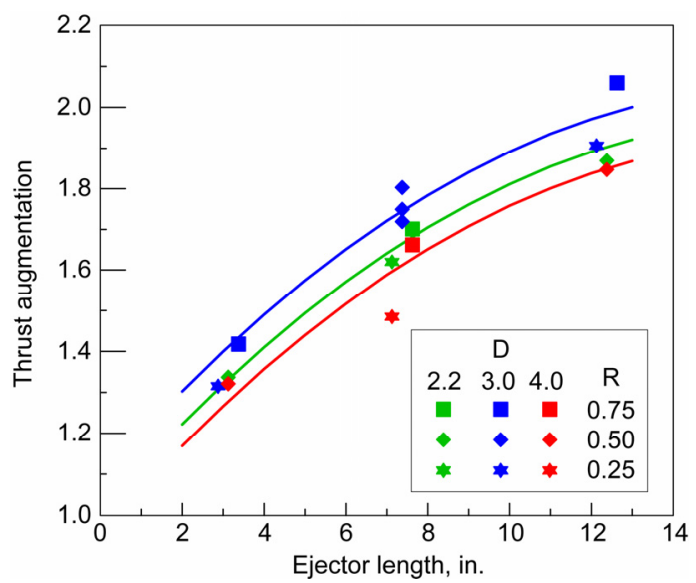

Figure 5.-Maximum thrust augmentation for each ejector plotted against ejector length. The lines are response surface contours for $\mathrm{R}=0.5$, and $\mathrm{D}=2.2(-), \mathrm{D}=3(-)$ and $\mathrm{D}=4(-)$. Frequency $=20 \mathrm{~Hz}, \phi=1.2$.

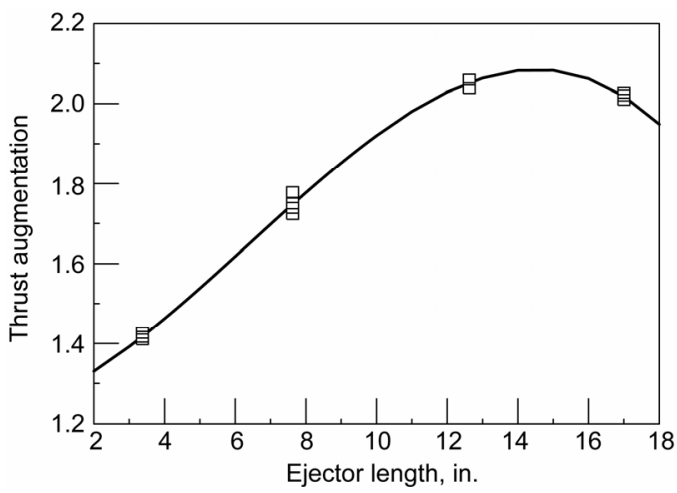

Figure 6.- The effect of varying the ejector length for the 3 inch diameter, 0.75 inch inlet radius ejector. The frequency was $20 \mathrm{~Hz}$., equivalence ratio $=1.2$.

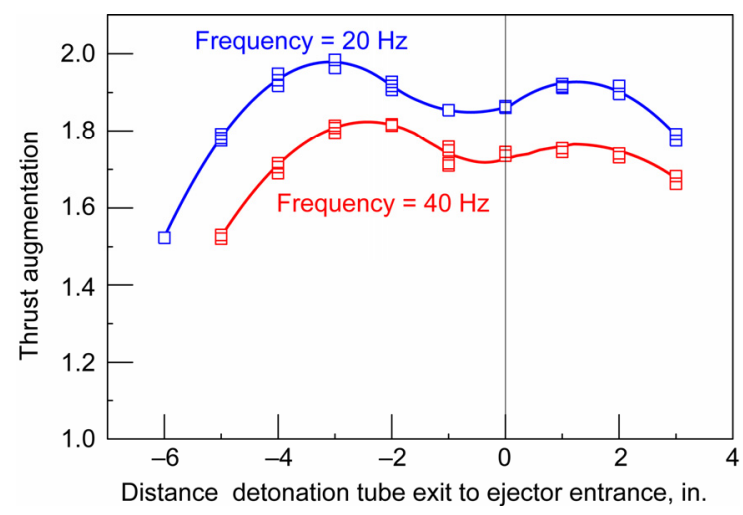

Figure 7.-Thrust amplification as a function of distance between the detonation tube exit and the ejector entrance. Positive values indicate ejector entrances downstream of the detonation tube exit. The results are for two different frequencies. The equivalence ratio $=1$. The ejector length was 17 inches, the diameter was 3 inches, and inlet radius 0.75 inches. 
also the effect of changing the position of the entrance. To minimize the number of runs needed, the ejector entrance to detonation tube exit distance was set to the values giving the maximum augmentation in the runs of section $\mathrm{C}$, shown in figure 7 , namely -3 inch, and +1.5 inches. However, since prior experience with this ejector had shown its best performance occurred at longer positive distances than those used for the ejectors of figure $3(\mathrm{a})$, a distance of +3 inch was also used. For these tests, the frequency was $20 \mathrm{~Hz}$, the equivalence ratio was 1 , the fill fraction was 1.05 , and the duty cycle was 55 percent.

Since the tests of section $\mathrm{C}$ had shown quite large thrust augmentations, with apparently similar geometry to that used by Shehadeh et al. (ref. 1), but with a different thrust measuring technique, this raised the question as to whether the technique itself was in error. Consequently, for these runs, an additional technique, measuring thrust by the calibrated extension of a spring was also used. The results of the tests are given in figure 8. Although the spring extension system gave lower values of thrust than the thrust plate, it can be seen that the thrust amplifications of the two techniques were in good agreement. A thrust amplification of 2.5 was observed at $x=+3$ inches, and it appears that even higher

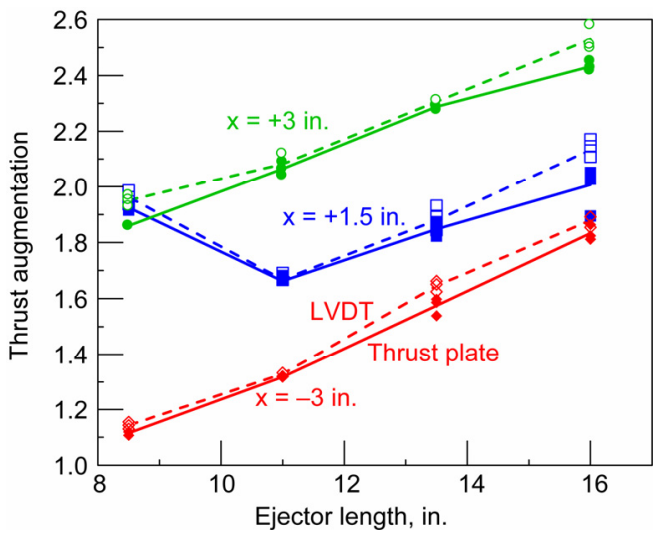
values might be achieved at longer lengths.

\section{Discussion}

Higher values of thrust augmentation were found in this study than were found by previous workers (refs. 1 to 3), which raises the question as to how this could be. Since both the thrust plate and spring-displacement methods of measuring augmentation gave essentially identical results for thrust augmentation, it would not seem to be an error in technique. Presumably then, it rests with the details of the detonation tube and ejectors used. Details of each experiment, with the ejectors giving the maximum augmentation are listed in table 3 .

Most striking is the discrepancy between the low thrust augmentation seen by Rasheed et al. (ref. 3), and values found by other workers. A major difference between Rasheed et al., and the present work is the value of $\tau$, the ratio between the extra thrust produced by the detonations relative to the thrust generated by the air flow itself. Unfortunately, $\tau$ is not known for Shehadeh et al. (ref. 1), and Allgood et al. (ref. 2). The thrust of the jet without an ejector is:

The thrust with an ejector is:

$$
T_{\text {jet }}=T_{\text {air }}+T_{\text {det }}
$$

$$
T_{\text {ejector }}=\alpha_{\mathrm{ss}} \cdot T_{\mathrm{air}}+\alpha_{\mathrm{det}} \cdot T_{\mathrm{det}}
$$

So that the thrust augmentation is:

$$
\alpha=T_{\text {ejector }} / T_{\text {jet }}=\left(\alpha_{\mathrm{ss}}+\alpha_{\text {det }} \tau\right) /(1+\tau)
$$

\begin{tabular}{|c|c|c|c|c|c|c|c|c|c|}
\hline Paper & Fuel & Oxidiser & $\tau$ & $f(\mathrm{~Hz})$ & $D / D_{\text {tube }}$ & $L / D$ & $R / D$ & $\alpha$ & Ejector Geometry \\
\hline Shehadeh et al. (ref. 1) & Ethylene & $\mathrm{N}_{2}-\mathrm{O}_{2}$ mix & - & 10 & 2.55 & 8.36 & 0.087 & 1.4 & Straight \\
\hline Allgood et al. (ref. 2) & $\mathrm{H}_{2}$ & Air & - & 30 & 2.75 & 14.ff & Bell & 1.65 & Straight + Diffuser \\
\hline 6 & “6 & "6 & - & "6 & " & “ & "6 & 1.28 & Straight \\
\hline Rasheed et al. (ref. 3) & $\mathrm{H}_{2}$ & Air & 0.77 & 10 & $2.0^{*}$ & 3.8 & 0.13 & 1.16 & Straight \\
\hline This work & $\mathrm{H}_{2}$ & Air & 9 & 20 & 3.0 & 4.2 & 0.25 & 2.05 & Straight + Diffuser \\
\hline "6 & "6 & “6 & " & "6 & " & $>5.3$ & "6 & 2.5 & Tapered \\
\hline
\end{tabular}

TABLE 3.-COMPARISON OF RESULTS AND CONDITIONS OF DIFFERENT WORKERS

${ }^{*} D / D_{\text {tube }}=3$ might have given a higher value of $\alpha$ at a larger value of $L / D$ than was tested

The air is flowing continuously in both the experiments of Rasheed et al., and the present work. Consequently the thrust augmentation of the air flow (and the air/fuel mixture also) will be the steady state value. A graph of steady state thrust augmentation against the ratio of ejector area ratio to jet area given by Porter and Squyers (ref. 9), indicates that for Rasheed et al., a value of $\alpha_{\mathrm{ss}}=1.1$ is not unreasonable, and a value of $\alpha_{\mathrm{ss}}=1.2$ is appropriate for 
the area ratio of the present work. This latter value is in line with rather crude experimental observations also. For the present experiment, using $\alpha_{\mathrm{ss}}=1.2$, and $\tau=9$, and assuming a value of $\alpha_{\mathrm{det}}=2.14$, gives the observed value of $\alpha=2.05$ when inserted into equation (5). Thus $\alpha$ and $\alpha_{\text {det }}$ are not very different. Rasheed et al. did not define thrust augmentation in the same way as is done here. Instead, they called $T_{\text {det }}$ the base thrust, and used this in the denominator for thrust augmentation. Despite this, they only achieved a thrust augmentation of 1.16, which they point out is in line with values for steady state thrust augmentation from Porter and Squyers (ref. 9). Their best ejector was at a smaller ratio of $D / D_{\text {tube }}$ than the optimum found here, with a smaller $L / D$, and a smaller $R / D$, and was also a straight ejector. However, Allgood et al. (ref. 2), and Shehadeh et al. (ref. 1), had achieved thrust augmentations of 1.28 , and 1.4 respectively, using straight ejectors, but at larger $D / D_{\text {tube }}$ and $L / D$ ratios. As pointed out above, the value of $\tau$ used by Rasheed et al. is only 0.77 , compared with 9 found in the present work. This means that their unsteady component of thrust is quite small, which probably leads to low thrust augmentation. Thus, while it can not be stated definitely, it does seem probable that the low value of thrust augmentation seen by Rasheed et al. is a result of non-optimum ejector geometry combined with a low value of $\tau$.

It was stated above that the statistical experiment was run at an equivalence ratio of 1.2 , and only at positive values of $\mathrm{x}$. In figure (7), which was run at an equivalence ratio of unity, it is seen that at positive $x$, the maximum thrust augmentation at $20 \mathrm{~Hz}$ is 1.9 , and at $40 \mathrm{~Hz}$ is 1.75 . Interpolating to $30 \mathrm{~Hz}$ would give a value of 1.82 . Allgood et al. ran at a frequency of $30 \mathrm{~Hz}$, and measured a maximum thrust augmentation of 1.65 at positive $x$, but their ejector was shorter than the optimum length, and therefore could possibly have reached a higher value. Thus their result does not seem greatly disparate with the present result.

The statistical experiment showed that there is an optimum value of $D / D_{\text {tube }}$ around 3.2. Unfortunately, this was for an equivalence ratio of 1.2, and a fill factor of 1.4. If, as been shown for other unsteady thrust augmentation measurements (refs. 10 and 11), the optimum ejector diameter is approximately equal to the size of the vortex ring generated on each pulse, it is probably independent of equivalence ratio. This needs to be confirmed, however. More disturbing is that the fill factor was 1.4, which means that there was a large region of un-ignited fuel-air mixture outside the tube when the detonation reaches the end of the tube. Since the critical diameter for near stoichiometric hydrogen-air mixtures is $20 \mathrm{~cm}$ (ref. 12), the detonation will quench on leaving the tube. However it will still cause the mixture to burn as a deflagration. Thus this may be the cause of the higher thrust augmentation seen at $\phi=1.2$ when the fill fraction was 1.4 , as against that seen at $\phi=1$, with a fill fraction of 1.05 .

Planar DPIV measurements of the vortex ring emerging from the detonation tube made by Opalski et al. (ref. 7) show that the size of the vortex ring is about 3.6 inches in diameter (fig. 9), where the size is defined as the diameter at which the vorticity goes to zero. The optimum ejector diameter was found to be 3.2 inches, and so is slightly smaller than the size of the vortex ring. The size of the vortex ring was the same for both values of equivalence ratio used.

Depending on whether or not the term in $b_{33}$ in the response surface model is retained, the optimum value of inlet nose radius is either 0.85 inches, or as large as possible. The term $b_{33}$ has only an 80 percent confidence level, and so it is not clear that it should be retained. Thus the exact size of the optimum nose radius is indefinite, but it can be said that it should be 0.85 inches or larger. This is larger than most of the rounded inlets used by the other workers, and needs further confirmation.

From the combined results of all the experiments in table 3, it seems clear that an ejector with a diffusing tailpiece is better than a straight ejector, and a tapered ejector is better than either of the other two.
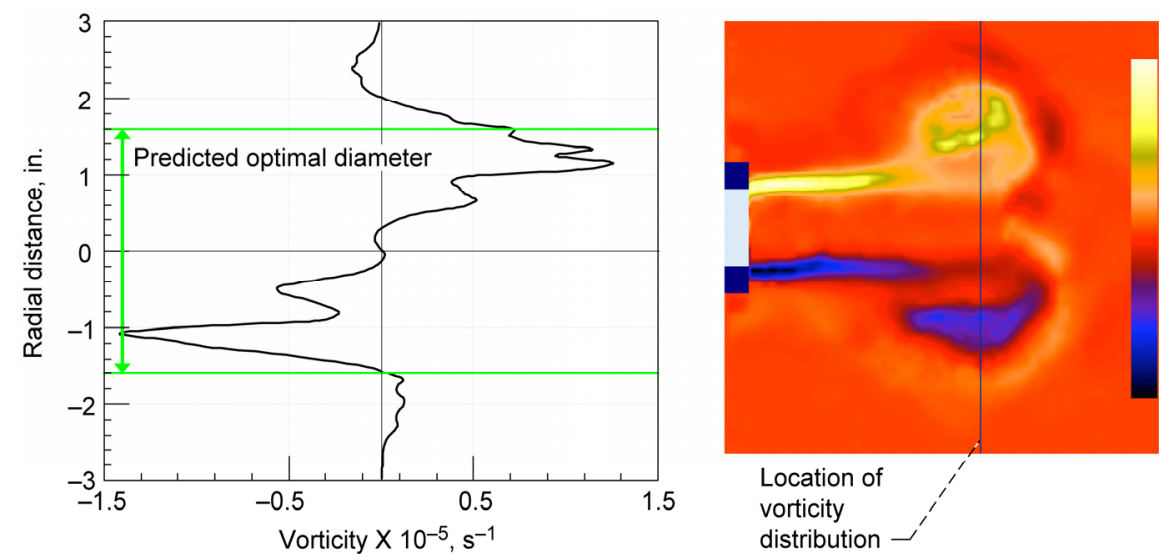

Figure 9.-DPIV measurement of vorticity in the vortex ring emerging from the pulsed detonation tube. 


\section{Conclusions}

Experiments with the 1 inch diameter pulsed detonation tube, using a statistical design of experiment have shown that there is an optimum diameter for an unsteady ejector driven by detonations, such that the ratio $D / D_{\text {tube }}=3.2$. The optimum length to diameter ratio for the ejector was found to be 5 . A fairly large inlet radius gives the best results, with a predicted optimum at $R / D=0.27$ or larger. Thrust amplifications at a frequency of $20 \mathrm{~Hz}$ were larger than those at $40 \mathrm{~Hz}$. Higher thrust amplification was also seen at an equivalence ratio of 1.2 than was seen at an equivalence ratio of 1.0. The thrust amplification depends on the distance between the detonation tube exit and the ejector entrance, with maxima at both positive and negative values of this distance. For both 20 and $40 \mathrm{~Hz}$ operation, the maxima with the ejector entrance upstream of the detonation tube exit were higher than the maxima with the ejector entrance downstream of the detonation tube exit. Finally, a tapered ejector showed a thrust augmentation value of 2.5 at $20 \mathrm{~Hz}$, with augmentation apparently still increasing with length at the longest length used.

\section{References}

1. Shehadeh, R., Saretto, S., Lee S.-Y., Pal S., and Santoro, R.J. "Thrust Augmentation Experiments for a Pulse Detonation Driven Ejector," Paper AIAA-2004-3398, presented at the $40^{\text {th }}$ AIAA/ASME/SAE/ASEE Joint Propulsion Conference, Fort Lauderdale, Florida (2004).

2. Allgood, D., Gutmark, E., Hoke, J., Bradley, R., and Schauer, F. "Performance Measurements of Pulse Detonation Engine Ejectors," Paper AIAA-2005-223, presented at the $43^{\text {rd }}$ AIAA Aerospace Sciences Meeting and Exhibit, Reno, Nevada (2005).

3. Rasheed, A., Tangirala, V., Pinard, P.F., and Dean, A.J. "Experimental and Numerical Investigations of Ejectors for PDE Applications," Paper AIAA-2003-4971, presented at the $39^{\text {th }}$ AIAA/ASME/SAE/ASEE Joint Propulsion Conference, Huntsville, Alabama (2003).

4. Groeschel, E., Tsuei, H.-H., Xia, G., and Merkle, C.L. "Characterization of Thrust Augmentation by Unsteady ejectors," Paper AIAA-2003-49970, presented at the 39 Conference, Huntsville, Alabama (2003).

5. Paxson, D.E., Wilson, J., and Dougherty, K.T. "Unsteady Ejector Performance: An Experimental Investigation using a Pulsejet Driver," Paper AIAA-2002-3915, presented at the $38^{\text {th }}$ Joint AIAA/ASME/SAE/ASEE Propulsion Conference, Indianapolis, IN (2002).

6. Wilson, J., and Paxson, D.E. "Unsteady Ejector Performance: An Experimental Investigation using a Resonance Tube Driver," Paper AIAA-2002-3632, presented at the $38^{\text {th }}$ Joint AIAA/ASME/SAE/ASEE Propulsion Conference, Indianapolis, IN (2002).

7. Opalski, A., Paxson, D.E., and Wernet, M.F., "Detonation Driven Ejector Exhaust Flow Characterization Using Planar DPIV," Paper AIAA-2005-4379, presented at the $41^{\text {st }}$ Joint AIAA/ASME/SAE/ASEE Propulsion Conference, Tucson, AZ (2005).

8. Mason, R.L. Gunst, R.F. and Hess, J.L. "Statistical Design and Analysis of Experiments: with Applications to Engineering and Science," Wiley, New York, 1989.

9. Porter, J.L., and Squyers, R.A. "A Summary/Overview of Ejector Augmentor Theory and Performance, Phase II - Technical Report”. Vought Corporation Advanced Technology Center Report No. R-91100/9CR-47A., 1979.

10. Paxson, D.E., Wernet, M.F., and John, W.T., "An Experimental Investigation of Unsteady Thrust Augmentation Using a Speaker-Driven Jet," Paper AIAA-2004-0092, presented at the $42^{\text {nd }}$ Aerospace Sciences Meeting and Exhibit, Reno, NV, (2004), also NASA/TM-2004-212909.

11. Wilson, J., "The Effect of Pulse Length, and Ejector Radius on Unsteady Ejector Performance," Paper AIAA-2005-3829, presented at the $41^{\text {st }}$ Joint AIAA/ASME/SAE/ASEE Propulsion Conference, Tucson, AZ (2005).

12. Knystautas, R., Guirao, C., Lee, J.H., and Sulmistras, A., "Measurements of Cell Size in Hydrocarbon-Air Mixtures and Predictions of Critical Tube Diameter, Critical Initiation Energy, and Detonability Limits," in Dynamics of Shock Waves, Explosions, and Detonations, vol. 94 of Progress in Aeronautics and Astronautics, edited by Bowen, J.R., Manson, N., Oppenheim, A.K., and Soloukhin, R.I., 1984. 
Public reporting burden for this collection of information is estimated to average 1 hour per response, including the time for reviewing instructions, searching existing data sources, gathering and maintaining the data needed, and completing and reviewing the collection of information. Send comments regarding this burden estimate or any other aspect of this collection of information, including suggestions for reducing this burden, to Washington Headquarters Services, Directorate for Information Operations and Reports, 1215 Jefferson Davis Highway, Suite 1204, Arlington, VA 22202-4302, and to the Office of Management and Budget, Paperwork Reduction Project (0704-0188), Washington, DC 20503.

\begin{tabular}{|l|l|l}
\hline 1. AGENCY USE ONLY (Leave blank) & $\begin{array}{c}\text { 2. REPORT DATE } \\
\text { August } 2005\end{array}$ & $\begin{array}{c}\text { 3. REPORT TYPE AND DATES COVERED } \\
\text { Technical Memorandum }\end{array}$ \\
\hline
\end{tabular}

4. TITLE AND SUBTITLE

5. FUNDING NUMBERS

Parametric Investigation of Thrust Augmentation by Ejectors on a Pulsed

Detonation Tube

6. AUTHOR(S)

WBS-22-708-03-05

Jack Wilson, Alexandru Sgondea, Daniel E. Paxson, and Bruce N. Rosenthal

7. PERFORMING ORGANIZATION NAME(S) AND ADDRESS(ES)

National Aeronautics and Space Administration

John H. Glenn Research Center at Lewis Field

Cleveland, Ohio 44135-3191

8. PERFORMING ORGANIZATION

REPORT NUMBER

E-15182

9. SPONSORING/MONITORING AGENCY NAME(S) AND ADDRESS(ES)

National Aeronautics and Space Administration

Washington, DC 20546-0001

10. SPONSORING/MONITORING

AGENCY REPORT NUMBER

NASA TM-2005-213823

AIAA-2005-4208

\section{SUPPLEMENTARY NOTES}

Prepared for the 41st Joint Propulsion Conference cosponsored by the AIAA, ASME, SAE, and ASEE, Tucson, Arizona, July 10-13, 2005. Jack Wilson and Alexandru Sgondea, QSS Group, Inc., 21000 Brookpark Road, Cleveland, Ohio 44135; and Daniel E. Paxson and Bruce N. Rosenthal, NASA Glenn Research Center. Responsible person, Jack Wilson, organization code RTC, 216-433-1204.

12a. DISTRIBUTION/AVAILABILITY STATEMENT

12b. DISTRIBUTION CODE

Unclassified - Unlimited

Subject Categories: 02 and 07

Available electronically at http://gltrs.grc.nasa.gov

This publication is available from the NASA Center for AeroSpace Information, 301-621-0390.

13. ABSTRACT (Maximum 200 words)

A parametric investigation has been made of thrust augmentation of a 1-inch diameter pulsed detonation tube by ejectors. A set of ejectors was used which permitted variation of the ejector length, diameter, and nose radius, according to a statistical design of experiment scheme. The maximum augmentations for each ejector were fitted using a polynomial response surface, from which the optimum ejector diameters, and nose radius, were found. Thrust augmentations above a factor of 2 were measured. In these tests, the pulsed detonation device was run on approximately stoichiometric air-hydrogen mixtures, at a frequency of $20 \mathrm{~Hz}$. Later measurements at a frequency of $40 \mathrm{~Hz}$ gave lower values of thrust augmentation. Measurements of thrust augmentation as a function of ejector entrance to detonation tube exit distance showed two maxima, one with the ejector entrance upstream, and one downstream, of the detonation tube exit. A thrust augmentation of 2.5 was observed using a tapered ejector.

14. SUBJECT TERMS

Ejectors; Thrust augmentation; Pulsed detonation engines

\begin{tabular}{|c|c|}
\hline $\begin{array}{c}\text { 17. SECURITY CLASSIFICATION } \\
\text { OF REPORT }\end{array}$ & $\begin{array}{c}\text { 18. SECURITY CLASSIFICATION } \\
\text { OF THIS PAGE } \\
\text { Unclassified }\end{array}$ \\
Unclassified
\end{tabular}

NSN 7540-01-280-5500

\begin{tabular}{|l|l|} 
& $\begin{array}{c}\text { 15. NUMBER OF PAGES } \\
15\end{array}$ \\
\cline { 2 - 2 } & 16. PRICE CODE \\
\hline $\begin{array}{c}\text { 19. SECURITY CLASSIFICATION } \\
\text { OF ABSTRACT } \\
\text { Unclassified }\end{array}$ & 20. LIMITATION OF ABSTRACT \\
\hline
\end{tabular}

Standard Form 298 (Rev. 2-89)

Prescribed by ANSI Std. Z39-18 298-102 

